\title{
La construcción de un personaje: de Alonso Quijano a don Quijote
}

\author{
Carlos Miguez Macho*
}

El objeto de estas páginas es presentar un análisis clarificador del proceso que lleva a Alonso Quijano a convertirse en don Quijote, un tema que guarda estrecha relación con las consideraciones acerca de la personalidad del hidalgo y el carácter de la locura del caballero, y, en general, con el estudio teórico de la figura del personaje literario.

Aun sin perder de vista los datos que se pueden espigar en otros capítulos, lo cierto es que el espacio textual dedicado en la novela a la pre-historia de don Quijote se reduce, exclusivamente, a los cuatro primeros párrafos de la novela. De ellos, el primero nos habla del hidalgo, ya cincuentón, como individuo inserto en un determinado microcosmos vital, mientras que los otros tres abordan el proceso que finalmente lo ha de llevar a la locura.

De esta simple constatación empírica se deben extraer, al menos, dos consecuencias:

- Primera, que Alonso Quijano carece de importancia en la novela. Importancia no solo en el sentido de que casi no se nos habla de él, sino, sobre todo, en lo que se refiere a que don Quijote no está construido como personaje teniendo en cuenta de una forma siquiera mínimamente significativa la personalidad de Quijano.

- Segunda, que a la hora de abordar la reconstrucción del camino hacia la locura que sigue el personaje, no queda más remedio que enfrentarse ineludiblemente con la posibilidad de caer en un problema ya advertido en cierta exegesis de la novela: su «excesivo alejamiento a veces del texto del Quijote» $^{1}$.

* IES Ramón M. ${ }^{\text {a }}$ Aller Ulloa, Lalín (Pontevedra).

1. José Montero Reguera, «Mujer, erotismo y sexualidad en el Quijote», Anales Cervantinos, XXXII, 1994, p. 110. 
Sobre la primera consecuencia se irá dando cuenta, en general, a lo largo de estas páginas. Sobre la segunda, se impone de antemano observar que, aunque esa idea de alejamiento del texto es problemática, pues el ámbito de la hermenéutica comporta per se cierto distanciamiento de la literalidad, no es posible, sin embargo, no incluir claramente en ella la no poco frecuente operación crítica de extraer deducciones psicológicas o vitales acerca de los personajes a partir de un escaso corpus de datos, con el objeto de sustentar ciertos perfiles biográficos interesados.

El análisis de los personajes literarios está lleno de trampas. En su informe sobre la crítica centrada en la mujer, el erotismo y la sexualidad en el Quijote, José Montero Reguera señaló como reparos de carácter general a las aproximaciones psicoanalíticas y psicologistas a la figura de Alonso Quijano/don Quijote el que estas lleguen a considerar a los personajes «como si fueran personas de carne y hueso» o que apliquen «criterios o métodos de análisis de nuestra época a momentos históricos en que se desconocían» ${ }^{2}$. En la misma línea, Juan Bautista Avalle-Arce, a propósito también del psicoanálisis aplicado al Quijote, se manifestaba hace años de la siguiente manera:

Los arcanos psicológicos que encerraban las mentes de edades anteriores [...] apunta[ban] a nortes muy distintos a los de la edad de Freud, que, al fin y al cabo, es la nuestra. Válida y efectiva, sin embargo, es la aplicación de textos psicológicos del Siglo de Oro español para explicar mentalidades de esa época, o bien textos literarios de la misma ${ }^{3}$.

En relación con el tema que nos ocupa, estas citas nos permiten abordar dos aspectos esenciales del mismo. Por un lado, se plantea aquí la ya clásica discusión narratológica acerca de si el modelo de aproximación al personaje literario debe ser el estructural-actancial o el psicológico; por otro, se pone sobre el tapete la cuestión de si una vez aceptado este último modelo, debemos limitarnos al uso de teorías médicas contemporáneas al autor del texto o bien podemos manejar cualquier teoría a nuestra disposición.

Sobre la primera cuestión, a día de hoy, y después de la evolución hacia el psicologismo de figuras del estructuralismo como Barthes, parece claro que las dos aproximaciones son igualmente válidas, y que pueden manejarse en términos de complementariedad. De entrada, la consideración de los personajes literarios como personas reales de carne y hueso no puede entenderse como un error crítico, pues no deja de ser una herramienta interpretativa natural en cualquier recepción lectora, que no hace sino corresponder a los criterios de construcción del personaje empleados por su autor:

Cuando se psicoanaliza a los personajes de ficción como si fueran gente de verdad, puede que los críticos más obstinados tengan razón al poner objeciones a tal esfuerzo. Pero los personajes como construcciones narrativas

2. Ibíd., p. 109.

3. Juan Bautista de Avalle-Arce, Don Quijote como forma de vida, Valencia, Fundación Juan March-Castalia, 1976, pp. 99-100. 
necesitan términos para su descripción, y no hay razón para rechazar los que se extraen del vocabulario general de la psicología, moralidad y cualquier otro aspecto relevante de la experiencia humana ${ }^{4}$.

Ahora bien: una descripción basada en esa premisa debe ajustarse a unos mínimos principios de rigor. En concreto, parece claro que, al menos, es imprescindible tener muy en cuenta tres aspectos que condicionan a cualquier personaje literario:

- En primer lugar, que la especificación de las causas del perfil psicológico de un personaje de ficción es una tarea delicada, por cuanto no es posible acceder a ninguna información que no se halle explicitada en el texto; dicho de otra forma, la información sobre un personaje no solo es siempre incompleta sino que, más allá del texto, no existe. De ahí que, en muchas ocasiones, se trate de una tarea puramente inductiva, con todo lo que eso conlleva de hipotético.

— En segundo lugar, que el perfil psicológico de los personajes literarios puede no corresponderse, globalmente, a nada conocido en el ámbito de la realidad empírica, por más que los detalles que lo conforman sean bien conocidos; esto es, potencialmente es posible encontrarse con un personaje literario que no se adecue a ningún patrón psicológico conocido:

In general, there is no requirement or logical need for invented individuals to conform to any pattern of ontological regularity or even consistency formulated for the actual world. Standard logic and ontology may be waived, and the individual may be endowed with semantically incompatible properties ${ }^{5}$.

- Y, en tercer lugar, que una cosa es tomar a un personaje literario como un ser real y otra muy distinta es que eso justifique automáticamente las aproximaciones psicoanalíticas (o de otro tipo) al mismo.

Respecto a este último punto, en relación con la censura que a la aplicación de técnicas freudianas a la novela cervantina hay en las palabras de Avalle-Arce (crítica que, por lo demás, se podría compartir perfectamente), no se puede sino estar de acuerdo en este punto con Carroll B. Johnson ${ }^{6}$ : desde un determinado punto de vista, no resulta fácil de ver dónde estriba la diferencia de fondo que hay entre la aplicación de Freud, por un lado, y la aplicación de las teorías de Juan Luis Vives o de Huarte de San Juan, por otro ${ }^{7}$, a la hora de

4. Seymour Chatman, Historia y discurso. La estructura narrativa en la novela y en el cine, Madrid, Taurus, 1990, p. 148.

5. URI MARGOLIN, «Structuralist approaches to character in narrative: The state of the art», Semiotica, 75, 1989, 1-2, p. 11.

6. Véase Carroll B. Johnson, Madness and Lust. A Psychoanalytical Approach to "Don Quixote», Berkeley, University of California Press, 1983, pp. 4 y ss.

7. Véase Juan Bautista de Avalle-Arce, Don Quijote como forma de vida, cit., pp. 100 y ss. 
explicarnos a Alonso Quijano. Porque es evidente que de la misma forma que podemos cuestionar la validez de las teorías de Freud para los hombres de nuestro tiempo, igualmente podemos cuestionar, y de hecho lo hacemos y con más seguridad que en el caso anterior, las de Vives y Huarte para los del XVI-XVII. Además, hay que tener en cuenta que ni Huarte ni Vives tienen por objeto describir solo los comportamientos psicológicos propios de sus contemporáneos, sino que, como es lógico, elaboraron teorías patológicas generales que, implícitamente y como tales, tenían por objeto no circunscribirse a ninguna época histórica en particular.

Y aunque resulta obvio que la diferencia entre unos y otro está en que, evidentemente, Cervantes conocía a los primeros y no al segundo, lo cierto es que esto a lo que afecta es únicamente a cuál es la explicación médica que, siquiera de pasada, Cervantes sugiere en el texto en aras de una mayor verosimilitud, pero en ningún caso a la verdadera causa, que es independiente del momento histórico; lo que se supone que buscamos no es una explicación (la de Freud, la de Vives o la de quien sea) sino la explicación (que puede ser la de cualquiera de los anteriores o la de todos ellos juntos).

A este respecto, no hay que perder de vista el hecho de que la presencia en la caracterización del hidalgo de las teorías de Vives y de Huarte de San Juan no explica su locura sino que, por decirlo de alguna manera, pre-destina a Alonso Quijano hacia la misma. De hecho, no parecería razonable deducir que todos aquellos individuos que compartiesen los caracteres que definen a Alonso Quijano pudiesen llegar también a enloquecer.

Estas referencias médicas dentro de la propia novela son, quizá, la prueba más evidente de que Cervantes no contempló en absoluto la idea de vincular la locura de su personaje con complejos aspectos psicológicos. Dicho también de otra manera, y como recordábamos al principio, la propia novela, con su escasa atención a Alonso Quijano y con una explicación médica casi de compromiso al porqué de su locura, nos invita a no elucubrar en exceso sobre el asunto.

Evitar el alejamiento del texto es, sin duda, esencial para no caer, por ejemplo, en la trampa de leer los siglos XVI-XVII como si fuesen el XX sin tener en cuenta una adecuada perspectiva sociológica. Así, cuando Johnson, a partir de la lectura de las primeras líneas de la novela, dice de la vida del hidalgo que «is characterized by endless repetition of the same few elements ${ }^{8}$, lo que está haciendo no es sino proyectar sobre el tipo de vida del XVI-XVII el de nuestro tiempo. Dejando a un lado que conceptos como repetición y pocos elementos son extremadamente subjetivos, no se puede pretender equiparar el tempo vital de hace cuatrocientos años con el actual. Dicho de otra forma: la, desde nuestro punto de vista actual, monotonía de la vida de entonces no tenía por qué implicar sensación de monotonía en sus protagonistas.

En cuanto a la aplicación del psicoanálisis, la recreación que de la vida de Alonso Quijano ha hecho el mismo Johnson, y aun cuando se deba reconocer

8. Carroll B. Johnson, op. cit., p. 58. 
el esfuerzo que realiza por resultar riguroso, lo cierto es que no puede por menos de dejarnos bastante indiferentes por la sencilla razón de que, al final, el resultado no deja de parecer una ficción sobre otra ficción: más que iluminar la novela, lo que se consigue en casos como este es poner al investigador en un primerísimo plano, pues su recreación está impregnada de una subjetividad esencial; el texto literario es un pretexto para otro texto literario.

A esta opción de contar lo que no está escrito reconstruyéndolo intuitivamente, se contrapone la opción, menos espectacular sin duda, de un apegamiento al texto si no radical, sí cuando menos inexcusable como punto de partida de cualquier afirmación sobre el tema. Por lo demás, es difícil no convenir con Martín de Riquer cuando dice que «el Quijote es una novela clarísima, sin trampa de ninguna clase ${ }^{9}$; con independencia de que no se niegue la posibilidad de poder buscar explicaciones que indaguen aún más en lo sucedido en los textos, incluso sobrepasándolos, lo cierto es que, en numerosas ocasiones no se cae en la cuenta de que este es lo suficientemente claro como para poder dar él mismo todas esas explicaciones.

Según dice la historia, Alonso Quijano «los ratos que estaba ocioso, que eran los más del año, se daba a leer libros de caballerías» ${ }^{10}$. Aunque en más de una ocasión se ha dado por supuesto que la hidalguía de Alonso Quijano es un factor decisivo a la hora de entender su fuerte inclinación por tal tipo de libros, que le ofrecerían «la visión quimérica, idealizada hasta el desatino, de un mundo en que un pequeño noble podía realizar las más estupendas hazañas y alcanzar las cimas más altas...» ${ }^{11}$, lo cierto es que establecer un vínculo de este tipo como fundamentador de su afición no es más que super-interpretar el texto. Si tal cosa fuese cierta, de ello sin duda se podría deducir, en buena lógica, que solo los hidalgos sentirían «fuerte inclinación» por los libros de caballerías; sin embargo, sabemos con certeza, la propia novela lo explicita en varias ocasiones, que el éxito de estos libros se daba entre cualquier tipo de personas, ya fuesen curas, hidalgos, barberos, canónigos, venteros, etc.

Como el mismo don Quijote expone con claridad, las funciones psicológicas de esas lecturas no son propiedad de ningún tipo de persona en particular, pues a cualquiera «le destierran la melancolía que tuviere y le mejoran la condición, si acaso la tiene mala» $(\mathrm{I}, 50)$. Son efectos los que señala don Quijote que caracterizan a cualquier lectura tomada como un entretenimiento. Preguntarse por qué esos libros, y no otros, entretenían tanto a Alonso Quijano, con el objeto de utilizar ese argumento para describir indirectamente la personalidad de Alonso Quijano, es una perversión crítica: no hay nada en el texto que nos

9. Martín De RiQuer, «Introducción», Don Quijote de la Mancha, Miguel de Cervantes, Barcelona, Planeta, 1985 , p. XLIII.

10. Todas las citas de la novela están tomadas de la edición del Instituto Cervantes dirigida por Francisco Rico (Barcelona, Galaxia Gutenberg-Círculo de Lectores, 2004).

11. Francisco Rico y Joaquín Forradellas, «Lecturas del Quijote. Capítulo I», Miguel De Cervantes, Don Quijote de la Mancha: volumen complementario, Francisco Rico (dir.), Barcelona, Crítica-Instituto Cervantes, 2005, p. 17. 
permita afirmar que el hidalgo estuviese necesitado de entretener su imaginación con ese tipo de fantasías y no con otras; no hay nada que nos lleve a considerar a Alonso Quijano como un frustrado existencial que a través de los libros de caballerías consigue, primero, evadirse, de una realidad insatisfactoria para luego (re)crearla él mismo. El que don Quijote lea libros de caballerías, y no otros, es una necesidad impuesta por Cervantes, no por la personalidad de Alonso Quijano.

De ahí que la novela, al no dedicar atención a este asunto, sea muy clara al respecto: en lo único que se puede convenir es, como ya se ha indicado, en que el hecho de que Alonso Quijano sea un hidalgo ayuda a la verosimilitud de la historia, en los mismos términos que ayudaría el que si, por ejemplo, su locura consistiese en creerse un mago como Merlín nuestro protagonista fuese médico de profesión.

Por razones parecidas, vincular en cualquier sentido una hipotética, por textualmente indemostrable, «vida vegetativa de [...] hidalguete de aldea» con el hecho de hacerse escritor o caballero andante ${ }^{12}$ es algo que también carece de fundamento alguno. El único vínculo razonable entre Alonso Quijano y don Quijote, y, por lo demás, textualmente relevante, es el del contraste: Alonso Quijano pasa de la vida apacible y socialmente normal de un hombre de cincuenta años a la vida aventurera y anormal de todo un caballero andante de cincuenta años.

Afirmar que la monotonía vital de Alonso Quijano, en relación además con el sistema social represivo en el que está inserto, es lo que le ha llevado a los libros de caballerías ${ }^{13} \mathrm{o}$, incluso, a la lectura en general («lector empedernido a falta de una vida apasionante que vivir» ${ }^{14}$ ), no es más que, otra vez, super-interpretar el texto: dejando a un lado algo tan obvio como que no se lee necesariamente para suplir alguna deficiencia vital, en ningún lugar de la novela se dice que su vida fuese monótona o, como ya hemos visto, que el hidalgo la sintiese como tal, ni cosa parecida; lo que se dice, y que en modo alguno tiene por qué implicar lo otro, es que, simplemente, su vida abunda en ratos de ocio («... eran los más del año...»). Obsérvese, por lo demás, que esta preeminencia del tiempo de ocio casi permitiría fundamentar la idea de que su vida no es precisamente monótona, pues solo una pequeña parte de la misma estaría regulada por actividades de inexcusable realización, impuestas y reguladas, por así decirlo, desde fuera, mientras que el resto estaría llena de actividades decididas y reguladas libremente por él. No son pocas, además, las que se citan en el texto: caza, lectura, conversación con sus amigos, fiestas, etc. Incluso, aun en su edad, Alonso Quijano es también un hombre enamorado, lo que no deja de ser un síntoma más de normalidad humana absoluta: «en doce años que ha que la quiero más que a la lumbre destos ojos que han de comer la tierra, no la

12. Véase Juan Bautista de Avalle-Arce, Nuevos deslindes cervantinos, cit., p. 239.

13. Véase Martine BigeArd, La folie et les fous littéraires en Espagne, 1500-1650, Paris, Centre de Recherches Hispaniques-Institut d'Études Hispaniques, 1972, p. 153.

14. Rogelio MiÑana, «El verdadero protagonista del Quijote», Cervantes, XXV, 2005, 2, p. 33. 
he visto cuatro veces, y aun podrá ser que destas cuatro veces no hubiese ella echado de ver la una que la miraba» $(\mathrm{I}, 35)$; nada más sabemos al respecto, por lo que no hay tampoco ninguna base ni necesidad para sugerir que «su experiencia con el sexo opuesto es extremadamente limitada» ${ }^{15}$.

Más allá, por tanto, de todas esas lecturas hasta cierto punto impostoras del texto, lo cierto es que la novela, en principio, no viene sino a presentarnos una situación humana completamente normal e, incluso, a lo que parece, intemporal. Cuando leemos que Alonso Quijano «olvidó casi de todo punto el ejercicio de la caza, y aun la administración de su hacienda», ¿no nos estamos encontrando simplemente ante la manifestación de los habituales estragos que causan determinados entretenimientos en la vida de quienes hacen un uso incontrolado de ellos?: por un lado, el abandono de los que hasta ahora habían sido sus entretenimientos predilectos; por otro, el abandono de sus obligaciones sociales. Recordemos cómo define tan contundentemente don Quijote lo que para él son los libros de caballerías: «son el regalo de mi alma y el entretenimiento de mi vida» (I, 23).

Tampoco resultan especialmente contrarios a esta hipótesis de normalidad algunos ejemplos paralelos aducidos al respecto (no todos, pues algunos, que sí nos presentan a locos, no son comparables con la situación de Alonso Quijano), como por ejemplo los que nos hablan de personajes que se saben de memoria ciertas novelas o de familias que lloran porque se ha muerto Amadís ${ }^{16}$, pues no hacen sino recordarnos lo que no es más que un conjunto de efectos inherentes a las obras de arte, efectos que van desde la catarsis clásica hasta la simple sonrisa, pasando por empatías radicales con los personajes hasta el punto de hacer suyas determinadas actitudes y formas de vivir. Se podrá discutir teóricamente la consideración de los personajes literarios como si se tratasen de personas reales, pero lo que no se puede es, ante una descripción de lo que no son más que efectos básicos de cualquier obra artística, buscar una explicación que pretenda conferir una complejidad al texto que este, de forma evidente, no presenta.

Reiterando lo ya dicho, lo cierto es que nos estamos moviendo, de momento, en terrenos harto conocidos que entran claramente en los ámbitos de la llamada adicción: aficiones, ya sea la caza, la lectura o cualquier otra, que, aunque han evolucionado hacia la obsesión, entran siempre, en su origen, dentro de actividades elegidas libremente por los individuos de acuerdo con sus gustos.

Así, el punto de inflexión en todo el proceso que lleva a Alonso Quijano a convertirse en don Quijote es, sin duda, la progresiva invasión que la actividad lectora va haciendo de aquellos ratos que no son de ocio: los del cuidado de la hacienda. El momento es relevante y no debe ser pasado por alto con relación a una tentativa de caracterización del hidalgo: nos encontramos o bien ante una actitud más propia de niños o adolescentes (que descuidan el estudio por

15. Ibíd., p. 45.

16. Véase Martín de RiQuer, op. cit., pp. XLIII-XLIV. 
los juegos, por ejemplo), o bien de adultos con problemas serios de autocontrol, que quizá (solo «quizá») puedan derivarse de problemas sin solucionar en su existencia cotidiana. En todo caso, y dado que el texto no ofrece información alguna sobre posibles motivaciones, lo cierto es que no debemos tener reparos en afirmar que Alonso Quijano, un cincuentón, en este momento de su vida se comporta como un irresponsable. El mismo narrador, su mayor crítico a lo largo de toda la novela, es claro en la descripción de su actitud al comentar que el paso más allá que da Alonso Quijano al vender algunos de sus bienes «para comprar libros de caballerías en que leer» es un «desatino» que se alcanza por vía, simplemente, de la «curiosidad». Nótese bien, además, el «en que leer»: lo fundamental hasta ahora no es que lea libros de caballerías sino que lea en exceso.

La distinción es relevante por cuanto a través de ella se nos informa de que su obsesión no parece ser tanto la lectura de libros de caballerías como la simple lectura (por más que, como ya hemos dicho, la materia de estos pueda serle especialmente grata al personaje). Esta última impresión acerca de la índole exacta de su adicción viene avalada además por su preferencia por un autor, Feliciano de Silva, que no lo es solo de libros de caballerías, y al que, en concreto, admira por la «claridad de su prosa y entrincadas razones», como así lo atestigua la famosa cita de la razón de la sinrazón que, por lo demás, es de contenido amoroso.

El pasmo de Alonso Quijano por esas «entrincadas razones» nos permite también extraer algún rasgo más de la personalidad del hidalgo: la simpleza de Alonso Quijano es manifiesta. De hecho, es «con estas razones», y no con los sucesos fantásticos de los libros de caballerías, por lo que «perdía el pobre caballero el juicio». La mente de Alonso Quijano flaquea cuando se enfrenta a unos discursos ampulosos y ridículos ante los que se desvela «por entenderlos y desentrañarles el sentido»; $y$, según parece plausible, esto es algo que no lo hace por loco o enfermo sino por simple. Ni que decir tiene que, por otro lado, es insostenible cualquier sugerencia acerca de un supuesto control de la situación por parte del hidalgo: Alonso Quijano se vuelve loco y, porque se vuelve loco, puede aparecer en escena don Quijote. Don Quijote no es una creación consciente de Quijano, no es el resultado de una decisión lúcida de una persona que «ha decidido dar un giro radical a su vida ${ }^{17}$, sino el resultado de un trastorno mental.

En tanto que esto es así, la percepción sobre la inteligencia de Alonso Quijano/don Quijote ha sido tradicionalmente sobredimensionada (se le ha llegado a comparar con Demócrito ${ }^{18}$ ). Aunque podamos tener la impresión de que Alonso Quijano ha tenido que volverse loco para, en algunos casos, poder llegar a demostrar su inteligencia o su cultura, lo cierto es que en este punto no hay por qué exagerar: en modo alguno se puede deducir del texto que don Quijote sea especialmente sabio, culto o inteligente; lo único que está claro es que,

17. Rogelio MiÑana, op. cit., p. 33.

18. Juan Bautista de Avalle-Arce, Don Quijote como forma de vida, cit., p. 103. 
a pesar de estar loco, no es tonto ni ignorante, cosas que, dicho sea de paso, no tienen por qué excluirse entre sí. Por lo demás, como bien se ha preguntado algún crítico, «¿acaso la cultura literaria de don Quijote no la aporta el personaje de Quijano?» ${ }^{19}$.

Una vez fagocitado por la lectura, el paso siguiente en su peregrinar hacia la locura es el de la aplicación de principios de verosimilitud a lo sucedido en las historias que lo tienen atrapado. Se trata, obviamente, de un momento crucial. Es a partir de ahora cuando Alonso Quijano empieza a desmarcarse definitivamente de los límites de la ficción impuestos por las novelas. De hecho, la locura de don Quijote gravita más sobre su creencia de que lo que se cuenta en esos libros ocurrió de verdad, que en el hecho de que él se crea caballero andante, pues esto último no deja de ser una consecuencia lógica de lo anterior.

La conversación que mantiene con el cura y el barbero en el capítulo I de la segunda parte es capital con respecto a este asunto. Don Quijote deja claro en ella dos cuestiones: primero, que él sabe perfectamente que en su época ya no hay caballeros andantes, lo que significa que es perfectamente consciente de su excepcionalidad como tal; y, segundo, que su intención es que ese mundo, ética y estéticamente admirable, que se recrea en ellos tome cuerpo en su época. Su locura consiste, pues, en creer que convirtiéndose en caballero andante va a poder transformar la realidad. Al seguírsele el juego como se le sigue en la segunda parte de la novela, es evidente que algo ha conseguido. A este respecto, aunque su breve biografía de caballero andante que le relata al Caballero del Verde Gabán es parcialmente inexacta, por exagerada, tiene también su punto de verdad incuestionable: tanto cuando le dice que «quise resucitar la ya muerta andante caballería» como cuando recuerda que, nada más y nada menos, sus andanzas andan ya en libro.

Volviendo a su proceso hacia la locura, Alonso Quijano pasa, pues, por una etapa en la que intenta confrontar los principios de verosimilitud con lo que se cuenta en las historias de los libros de caballerías. Al seguir manejando como referente la realidad empírica, el hidalgo no está todavía loco. Seguimos dentro de los límites de la pasión puramente lectora, que es lo que tira realmente de él: como es frecuente en otras muchas personas (recuérdese, por ejemplo, que al canónigo que aparece al final de la primera parte, y según nos cuenta, también le pasó lo mismo [ver I, 48]), siente a veces el impulso de escribir él mismo. A este respecto, hay que subrayar también que no es exacto entender que esta opción de escribir, que no de hacerse escritor, quede «posibilitada sólo después de que el protagonista ha enloquecido» ${ }^{20}$, pues a estas alturas, como estamos viendo, don Quijote no está todavía loco. Por lo demás, insistiendo un poco más en lo, hasta este momento, normal de su actitud, debemos recordar que tanto el cura como el barbero se muestran igualmente seguidores acérrimos de los libros de caballerías, como demuestran sus referidas discusio-

19. Rogelio Miñana, op. cit., p. 32.

20. Juan Bautista de Avalle-Arce, Nuevos deslindes cervantinos, cit., p. 240. 
nes con el hidalgo en las que los contenidos de tales obras parecen tomarse como si fuesen reales; de nuevo, nada hay en esto de anormalidad: ¿cuántas veces no hemos hablado con otras personas de libros o películas con un entusiasmo que parecía que estuviésemos hablando de hechos o personas reales? Alonso Quijano, de momento, no es más que un lector especialmente voraz y entusiasta. Obsérvese, por lo demás, que esta percepción se vincula directamente con el fundamento de este trabajo, en el sentido de que los personajes de ficción terminan por tener un estatus de personas reales.

La etapa final viene marcada por la famosa frase que nos dice que «del poco dormir y del mucho leer, se le secó el celebro, de manera que vino a perder el juicio»: he aquí, por lo demás, la única indicación directa que el texto nos ofrece acerca de la causa directa de su locura. Obviamente, una exacta explicación científica de este tránsito final queda en manos de los especialistas médicos; sin embargo, por lo que respecta a su descripción literaria, es evidente que Cervantes, al dar cuenta de esa conversión a la locura en los términos intuitivos tan sencillos y claros en que lo hace, demuestra un nulo interés en darle un protagonismo innecesario al asunto.

En este sentido, resulta especialmente importante lo del no dormir: además de las razones aducidas por Avalle-Arce ${ }^{21}$, lo cierto es que este hecho supone un paso más, definitivo, en esa progresiva invasión que la lectura va haciendo de todo el tiempo del hidalgo. Alonso Quijano cae definitivamente en manos de la locura cuando en vez de controlar él su tiempo, este termina por ser controlado por los libros de caballerías: el lector que es Alonso Quijano deja de ser un simple lector activo para convertirse en un personaje más de lo que lee. El narrador explica, entonces, que el cerebro se le vacía de todo aquello que tiene que ver con la realidad y se le llena de todo lo que la ha sustituido, el mundo de los libros de caballerías. Consecuentemente, este mundo es ahora para el hidalgo la realidad: asume como realidades existenciales de igual categoría las de su ama y sobrina, y la de su probable venganza sobre Galalón.

Llegados a este punto, la simple relación extrema de un lector con sus lecturas queda completamente desbordada, y se entra así en los terrenos de la locura: lo que antes era algo puramente verbal ahora se ha hecho vida. De ahí que el paso final resulte lógico: dado que todo ese mundo es verdad, la posibilidad de convertirse en caballero existe, y más aún cuando en buena lógica caballeresca eso resulta absolutamente factible para un hidalgo como él. Al proclamar orgullosamente "yo sé quién soy» tras su primera derrota, no expresa ningún tipo de debilidad ni expone ningún resquicio por donde se vislumbre una cordura subyacente: quien habla es don Quijote, no Alonso Quijano, y lo que expone no es más que su conciencia de que en su mundo, en el mundo de los libros de caballerías, cualquier cosa es posible. El tránsito de la cordura a la locura es, para Alonso Quijano, la materialización del sueño de cualquier lector: convertirse en personaje de sus lecturas favoritas. 


\section{OBRAS CITADAS}

Avalle-Arce, Juan Bautista de, Nuevos deslindes cervantinos, Barcelona, Ariel, 1975.

- Don Quijote como forma de vida, Valencia, Fundación Juan March-Castalia, 1976.

Bigeard, Martine, La folie et les fous littéraires en Espagne, 1500-1650, Paris, Centre de Recherches Hispaniques - Institut d'Études Hispaniques, 1972.

Chatman, Seymour, Historia y discurso. La estructura narrativa en la novela y en el cine, Madrid, Taurus, 1990.

Johnson, Carroll B., Madness and Lust. A Psychoanalytical Approach to «Don Quixote», Berkeley, University of California Press, 1983.

MARGOLIN, URI, «Structuralist approaches to character in narrative: The state of the art», Semiotica, 75-1/2, 1989, 1-24.

MiÑAnA, Rogelio, «El verdadero protagonista del Quijote», Cervantes, XXV, n. ${ }^{\circ}$ 2, fall 2005, 31-58.

Montero Reguera, José, «Mujer, erotismo y sexualidad en el Quijote», Anales Cervantinos, XXXII, 1994, 97-116.

Rico, Francisco y Joaquín Forradellas, «Lecturas del Quijote. Capítulo I», Miguel DE Cervantes, Don Quijote de la Mancha: volumen complementario, Francisco Rico (dir.), Barcelona, Crítica-Instituto Cervantes, 2005, 16-18.

Riquer, Martín De, «Introducción», Miguel De Cervantes, Don Quijote de la Mancha, Barcelona, Planeta, 1985.

Recibido: 3-9-2007

Aceptado: 26-5-2008 


\title{
Resumen
}

La conversión de Alonso Quijano en el loco don Quijote no obedece a complejas razones psicológicas o psicoanalíticas que puedan encontrarse en la vida del hidalgo castellano. Las distintas teorías expuestas sobre la vida de Alonso Quijano no son más que elucubraciones que se alejan excesivamente del texto y que eluden la explicación más sencilla, pero también más fiel, que la propia novela ofrece: las consecuencias inmediatas de la adicción de Alonso Quijano a un determinado tipo de entretenimiento tiene exactos paralelos en nuestro tiempo; su locura es un corolario literario que no necesariamente tiene por qué tener una explicación científica.

Palabras clave: Alonso Quijano. Adicción. Locura. Literalidad.

Title: The making of a character: from Alonso Quijano to don Quixote

\begin{abstract}
The transformation of Alonso Quijano into the insane don Quixote is not due to complex psychological or psychoanalytic reasons which may be found in the life of the Castilian nobleman. The different theories exposed about the life of Alonso Quijano are only reflections which diverge excessively from the text and elude the most simple — but also most faithful - explanation offered by the novel itself: the immediate consequences of Alonso Quijano's addiction to a specific type of entertainment have exact parallels in our time; his madness is a literary corollary which should not necessarily have a scientific explanation.
\end{abstract}

Key words: Alonso Quijano. Addiction. Madness. Literality. 